\title{
NEUTRONS IN CALORIMETER STRUCTURES
}

\author{
G. R. Stcvenson \\ CERN, Geneva, Switzerland \\ J. S. Russ \\ Carnegie-Mollon Universily, Pillsburgh PA 15213, U.S.A.
}

\begin{abstract}
The proposed high-encrgy, high-luminosity hadron colliders (SSC and L,IIC) present new, challenging radiation environirients for detector components. 'The universal need for calorimeter coverage in experiments at these colliders means that the full hadronic energy will be deposited in heavy malerials close to or interleaved with delectors and electronics. Neutron generation in the hadronic cascades becomes a major damage mechanism. In this paper, previous discussions of neutron fluences to be expected are updaled by new data, especially relating to the higher luminosity proposed for the IHC. Recent experimental checks of the conclusions from simulation studies are presenied.
\end{abstract}

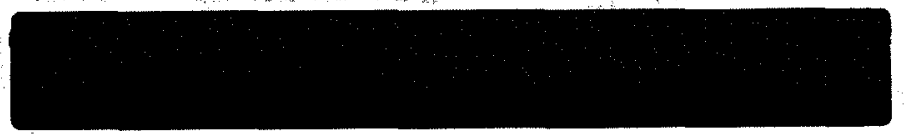

Paper presented al the 2nd International Conjerence on Advanced Technology and Parlicle Physics, Como, 11-15 Jun.e 1990.

Geneva, Switzerland

10 September 1990 


\section{Introduction}

Two years ago an SSC Task Group was formed to assess the radiation levels to be expected in an SSC detector. The findings of this Task (Group were published in an SSC report [1], and several shortened versions have been published since then (see [2] for example). The Task Group Report summarized experimental dala and Nonte-Carlo cascade simulations from which the following parameters could be derired for an idealized delector geometry: that of a hollow sphere of 2 metres internal radius where forward and backward cones in the high-rapidity region had been removed. The parameters of interest are:

- Dose to thin detectors in the central cavity from charged particles and photon conversions,

- Albedo neutron fluence in the central cavity region,

- Photon albedo,

- The maximum neutron fluence in the calorimeter, and

- The maximum dose in the calorimeter.

The purpose of this paper is to review other evidence which can help in determining especially those paramelers concerned with neutron fluence in the contral cavily and inside the calorimeter together with summarizing new data which have appeared since the Task Group met.

\section{Source Considerations}

Evidence was reviewed in the Task Group Report which showed that the the multiplicity of 'minimum bias', 'average' cvents can be well-approximated by a platcau function of rapidity where the number of particles produced per unit of pseudorapidity $\eta$ is a constant, $H$, independent of $\eta$ and they all have the same transierse momentum, i.e.

$$
\frac{\mathrm{d}^{2} N_{c h}}{\mathrm{~d} \eta \mathrm{d} p_{T}} \approx H \delta\left(p_{T}-<p_{T}>\right)
$$

Thus, integrating over $p_{T}$,

$$
\frac{\mathrm{d} N_{c h}}{\mathrm{~d} \eta}=H, \quad \text { and } \quad \frac{\mathrm{d} \eta}{\mathrm{d} \theta}=\frac{1}{\sin \theta} \quad \text { or } \quad \frac{\mathrm{d} \eta}{\mathrm{d} \Omega}=\frac{1}{2 \pi \sin ^{2} \theta} .
$$

This leads to the very simple relations:

$$
\frac{\mathrm{d} N_{c h}}{\mathrm{~d} \theta}=\frac{H}{\sin \theta}, \quad \text { or } \quad \frac{\mathrm{d} N_{c h}}{\mathrm{~d} \Omega}=\frac{H}{2 \pi \sin ^{2} \theta}, \quad \text { and } \quad E \approx p=\frac{\left\langle p_{T}\right\rangle}{\sin \theta} .
$$


in Tables 2 and 3. 'The numbers used by the Task (Yroup are a very close approximation to those found using ITTUJEI. It was also shown in the report [1] that the crror in the calculaled neutron production was negligible assuming a unique encrgy at a given angle instead of integraling over the whole hadron spectrum. However a word of caution is advisable: at low cnergies one enters into the domain of resonances in neutron production. In addition most particles are pions which when they interact will cause much higher nuclear excitation than protons. Thus the neutron production in objects close to sensitive cquipment placed inside the inner cavity may add to the albedo neul,rons reflected from the calorimeter. This problem rernains to be stuclied in detail.

Table 2: Mean Energy for p-p collisions

\begin{tabular}{|ccccccc|}
\hline $\begin{array}{c}\text { Angle } \\
\text { degrees }\end{array}$ & $\begin{array}{c}\text { SSC } \\
\text { SR-1033 }\end{array}$ & $\begin{array}{c}\text { SSC } \\
\text { DTU.JWL88 }\end{array}$ & $\begin{array}{c}\text { LIIC } \\
\text { SR--1033 }\end{array}$ & $\begin{array}{c}\text { LIIC } \\
\text { DTU.JET }\end{array}$ & $\begin{array}{c}\text { Spps } \\
\text { SR-1033 }\end{array}$ & $\begin{array}{c}\text { Sp } \bar{p} \\
\text { DTUJET }\end{array}$ \\
1 to 5 & 11.5 & 11.9 & 10.5 & 10.9 & 8.2 & 8.3 \\
5 to 10 & 4.6 & 3.6 & 4.2 & 3.4 & 3.3 & 2.8 \\
10 to 20 & 2.3 & 1.7 & 2.1 & 1.7 & 1.7 & 1.5 \\
20 to 40 & 1.22 & 0.89 & 1.12 & 0.79 & 0.87 & 0.80 \\
40 to 70 & 0.76 & 0.55 & 0.70 & 0.53 & 0.54 & 0.48 \\
70 to 90 & 0.62 & 0.49 & 0.57 & 0.18 & 0.44 & 0.41 \\
\hline
\end{tabular}

Table 3: IIadron Fluence for p-p collisions

\begin{tabular}{|c|c|c|c|c|c|c|}
\hline $\begin{array}{c}\text { Angle } \\
\text { degrces }\end{array}$ & $\begin{array}{c}\text { SSC } \\
\text { SR--1033 }\end{array}$ & $\begin{array}{c}\text { SSC } \\
\text { DUU.JP8 }\end{array}$ & $\begin{array}{c}\text { I,IIC } \\
\text { SR - } 10333\end{array}$ & $\begin{array}{c}\text { LIIC } \\
\text { DTU.JET }\end{array}$ & $\begin{array}{c}\text { Spps } \\
\text { SR:-1033 }\end{array}$ & $\begin{array}{c}\text { Spps } \\
\text { DIUJET }\end{array}$ \\
\hline 1 to 5 & 526.1 & 543.5 & $1 / 10.0$ & 110.0 & 195.0 & 185.0 \\
\hline 5 to 10 & 73.0 & 84.0 & 61.0 & 67.0 & 27.0 & 31.0 \\
\hline 10 to 20 & 18.5 & 21.0 & 15.5 & 17.5 & 6.9 & 8.3 \\
\hline 20 to 40 & 5.0 & 5.5 & 4.2 & 1.6 & 1.85 & 2.3 \\
\hline 40 to 70 & 1.85 & 1.95 & 1.55 & 1.65 & 0.69 & 0.84 \\
\hline 70 to 90 & 1.24 & 1.26 & 1.01 & 1.15 & 0.16 & 0.55 \\
\hline
\end{tabular}

\section{$3 \quad$ Neutron spectra in cascades}

Estimales of the energy spectrum of neutrons leaking radially from cylinders of different diameters where high-energy protons interact along the axis of the cylinder have been available for some considerable time. O'Brien and Mclaughlin solved the relevant Boltzmann 
The constants for use in these relations are given in Table 1. The values given are based more on extrapolations from experimental data than from Monte-Carlo simulation programs.

Table 1: Production constants for 'Threc Colliders

\begin{tabular}{|cccc|}
\hline Collider & SSC & LIIC & Spp̈S \\
Energy & $20+20 \mathrm{TeV}$ & $8+8 \mathrm{\Gamma eV}$ & $0.315+0.315 \mathrm{TeV}$ \\
& & & \\
$\mathrm{II}$ & 7.5 & 6.3 & 2.8 \\
$p_{T}$ & $0.60 \mathrm{GeV} / \mathrm{c}$ & $0.55 \mathrm{GeV} / \mathrm{c}$ & $0.42 \mathrm{GeV} / \mathrm{c}$ \\
\hline
\end{tabular}

The hadron energy spectrum averaged over the angular interval 5 to $10^{\circ}$ as calculated by the DTUJET program [3] is shown in Figure I for SSC, I.HC and Spp̈S cnergies. Most hadrons can be considered as pions. It will be seen that, the shape of the energy spectrum has very little dependence on primary proton energy: only the number of particles changes. This is also true al larger angles.

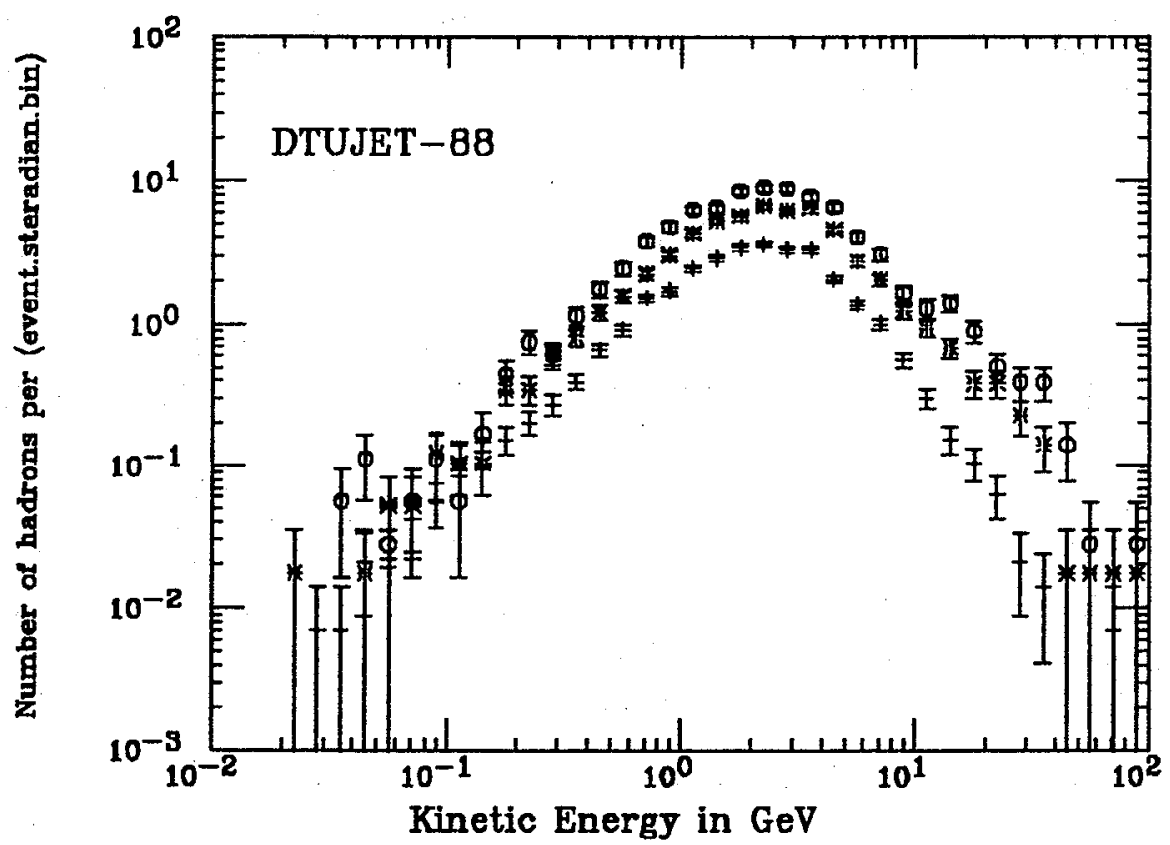

Figure 1: Iladron energy spectrum as calculated by D'TU.JT-88. The average over the angular interval 5 to $10^{\circ}$ is given for the SSC (o), LIIC (*) and SppS (+). The energy bins correspond to one-tenth of a decade on a logarithmic scale.

$\Lambda$ comparison of the mean encrgies and the lotal hadron fluence as determined from the DTUJET spectra and from the assumplions used in the Task Group Report are given 
equation using a the method of Spherical Ilarmonics [-1] and Figure 2 shows the result of such calculations for an iron cylinder (data taken from [5]). More recent. yy neutron spectra have been calculaled using Monle-Carlo simulalion programs. Figure 3 laken from the work of Tesch and 7azula is an example of these [6]. It will be seen that there is very little difrerence betwecn the two spectra, calculated sorne 20 years apart, especially in the energy region above $100 \mathrm{keV}$. This should lead to some confidence in using such generalized spectra in the cascade for damage prediction.

The maximum neutron fluence in a uranium/scintillalor calorimeler asscmbly is shown as a function of incident hadron encrgy in Figure I (taken from [1]). Most data points in this Figure come from Monle-Carlo simulations, but, there are two dala from experiments by Wigmans et al [7]. Another point derived from expcrimental data is that at $200 \mathrm{GeV} / c$ from work of Russ el al [8].

Since the Task Group Report was published new data arc available from an experiment similar to the latter in all respects except that the incident proton momentum was $21 \mathrm{GeV} / \mathrm{e}[9]$. In these experiments the measured radial proliles of neul,rons were identical at depths in the cascade equal to and grcatcr than the depth of cascade maximum. This means that the numerical adjustments for leakage and malerial dependence used in [1] are identical for the lwo cases. In scaling from calculalions and experincnis with different materials the data of Table 4 laken from [1] was used. (The lead:iron ratio appears to be confirmed after a recent experiment, using 200 GeV/e prolons on a lead structure in which the present authors were involved). The new data point al. 23 GeV falls close to the "best, fif" line of Figure 4. Thus there is no reason lo change the relation recommended by the Task Group for estimating the maximum neutron fluence:

$$
\int \phi \mathrm{d} a=18 \times\left(E_{k} / 1(\mathrm{ieV})^{0,67}\right.
$$

where $E_{k}$ is the incilent hadron energy. (The area-inlegraled fluence for one incident hadron is mumerically equal to the neutron flucnce for an incident, latron fluence of one per $\left.\mathrm{cm}^{2}\right)$.

These last two experiments were designed in part as benchmarks for Monte-Carlo simulation programs. 7azula has already simulated the low-energy neulron fluence distribution in the iron structure to beller than a factor of lwo everywlicre [10]. However Russ et al point out that very naive simulations can also predict neutron fluences to better than a. factor of two in such simple geomelrics. 


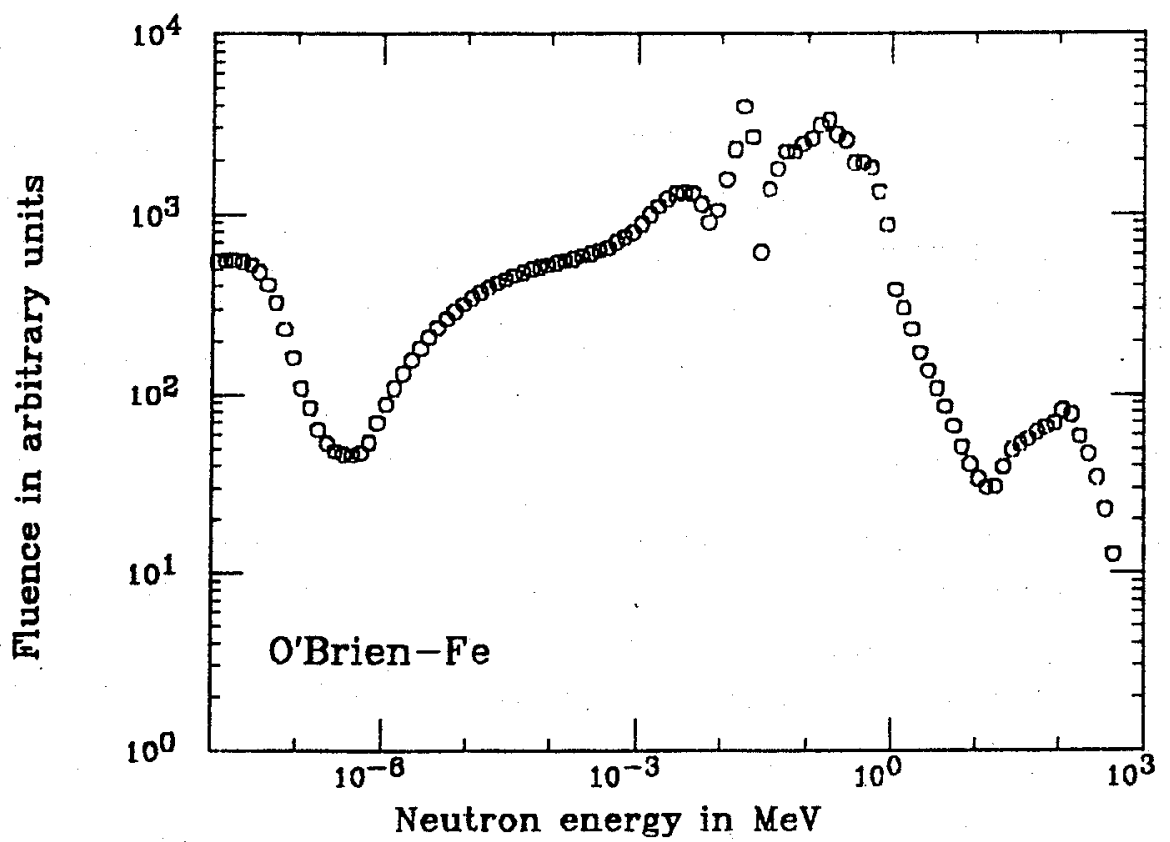

Figure 2: Neutron energy spectra from the analytic: calculations of ()'Brien [5]. The particles leak radially from a small iron cylinder bombarded by high-energy protons.

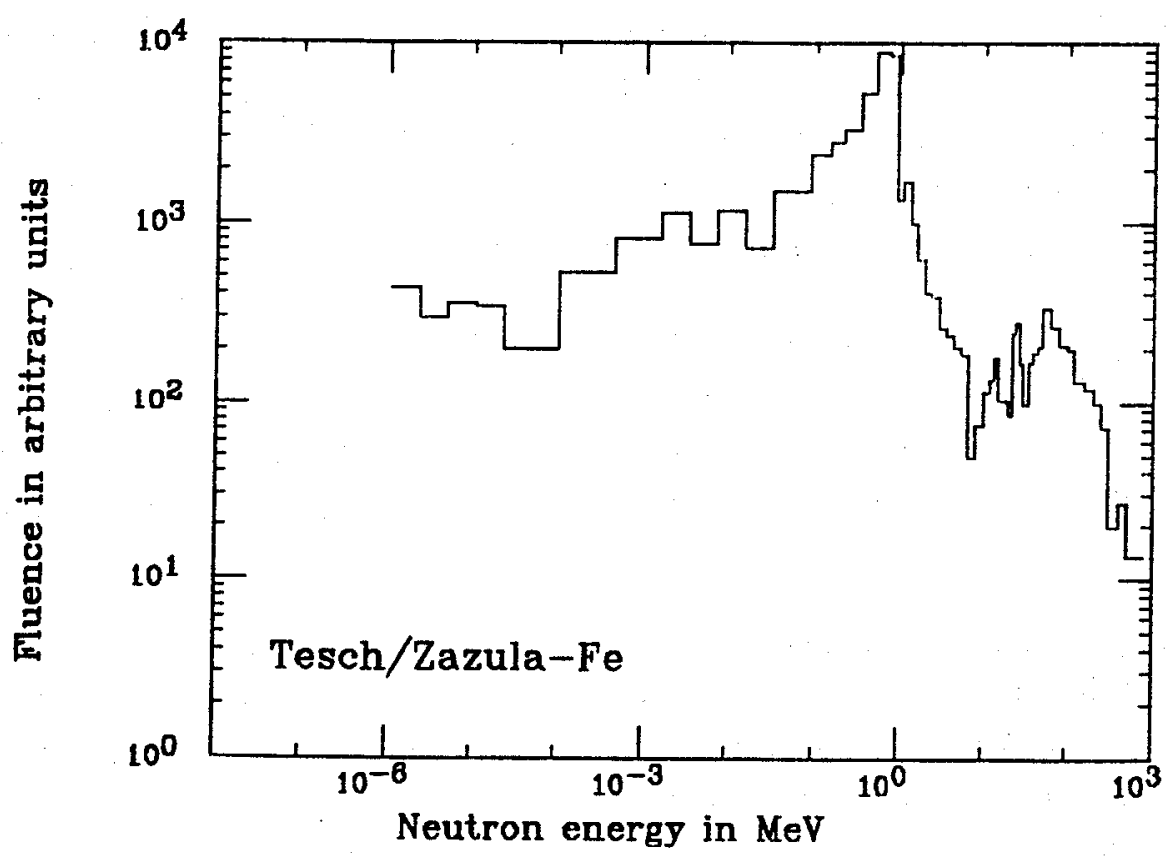

Figure 3: Neutron cnergy spectra from the Monte- (a)to calculations of Tesch and Zazula [0]. The parlicles leak radially from a small iron cylinder bombarded by high-energy protons. 


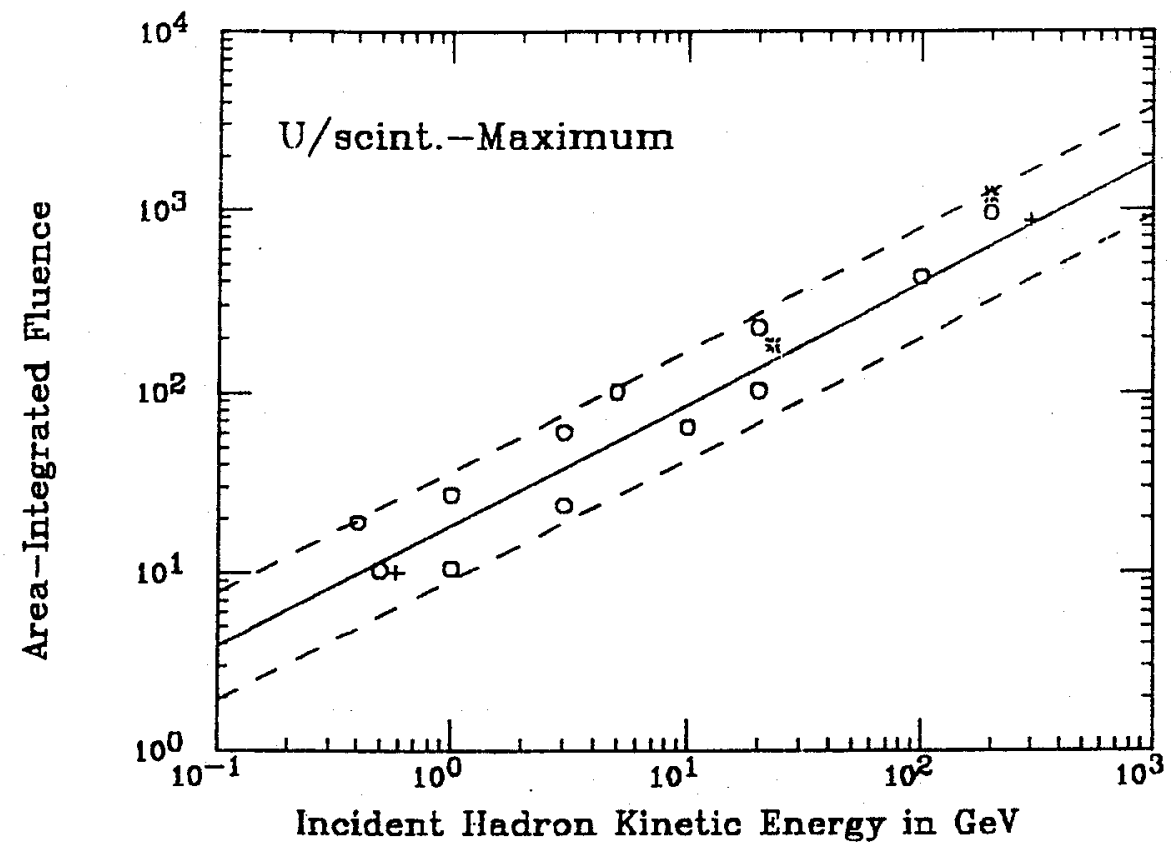

ligure t: Radially inlegraled neulen fluence al cascade maximum. The dala correspond to a uranium/scintillator calorimeder. ()pen circles (o) are from Monle-Carlo simulations. Vertical crosses $(+)$ are experimental dala from Wigmans [i]. Stars $\left(^{*}\right)$ are experimental

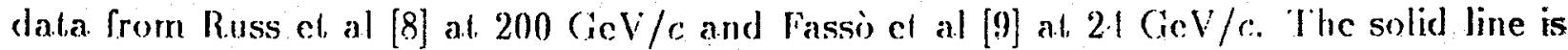
the equation $\int \phi \mathrm{d} a=18 \times\left(E_{k} / 1 \mathrm{GeV}\right)^{0.67}$, while the dashed lines are a factor of wo higher and lower.

Table 1: Neutron Production in Different Calorimelers

\begin{tabular}{|lc|}
\hline & Scale by \\
U-LAr or Si & 3.0 \\
Pb-LAr or Si & 1.7 \\
U-Scinl & 1.0 \\
In-LAr or Si & 0.7 \\
Pb-Scint & 0.5 \\
\hline
\end{tabular}

Coupling the mono energetic: source model discussed in the previons section with the above formula for nentron production in cascades, and cianging the basic conditions to the reference values of the l,IIC: ( i.e. a luminosity of $10^{31} \mathrm{~cm}^{-2}$, an anmual operaling time of $10^{7}$ seconds, an inclastic cross-section for p-p interactions of 60 mbarns and a reference alorimeler of a tollow lead sphere having an internal radius of 2 inetres wilh the forward and barkward cones at $\eta>6$ removed), the annual neul ron fluence ass a function of rapidily will be as shown in Figure ?. 


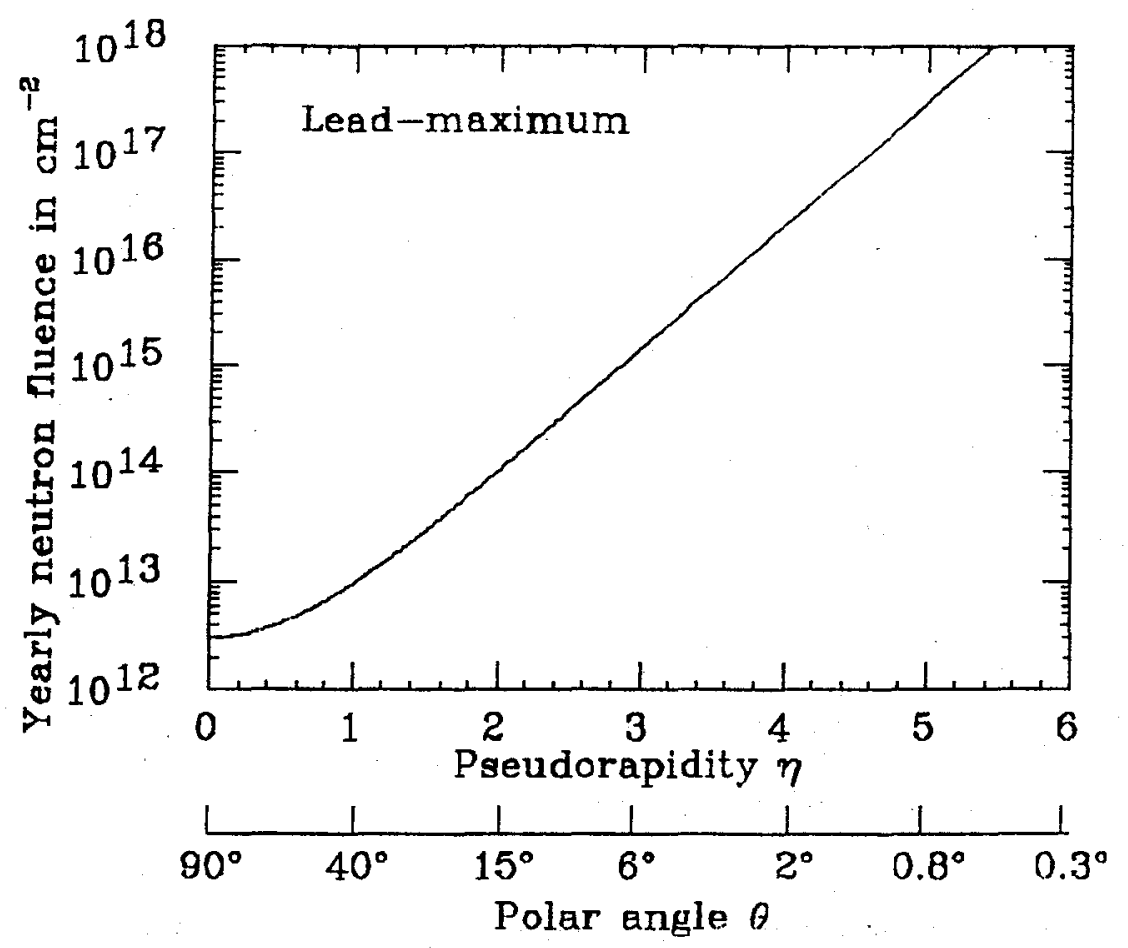

Figure 5: Maximum anmual neuteron fluences in a splierieal lead shell. The sphere has ari inner diameter of 2 meleres. Luminosity ele are for the reference L,Ile working conditions (see text).

The eflect of hydrogenoms material inside the calorimeter-absorber structure on the fluence of low-energy neutrons has long ben the subject of dehate. In a recent systematic.

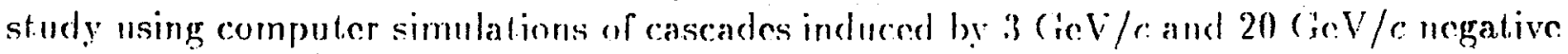
pions in $7.5 \mathrm{~mm}$ iron and 5 mum uranium calorimeler struetures, finpuno al al showed that

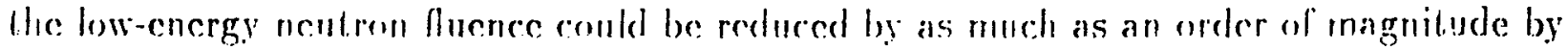
the insertion of polyelhylene layers of approximallely 1 com thickness [I l]. Their paper also shows the change is noutron spectrum and the change in the predicted damage in silicon as a function of thickness. Ilowerer the practicability of introducing a hydrogenoms material only for reducing the effect of neutrons where it is ust, required for calorimetric purposes remains open lo question.

\section{Albedo Neutrons}

The Task Group Report [1] also summarized eslimales of the number of neutrous leaving the front face of a uranium/scintillator calorimeter assembly as a function of incident hadron energy. This is gien in ligure 6. The new dala point from the 23 (iev experiment [9] is also indicaled and it will be seen that it fits in with the other data. 


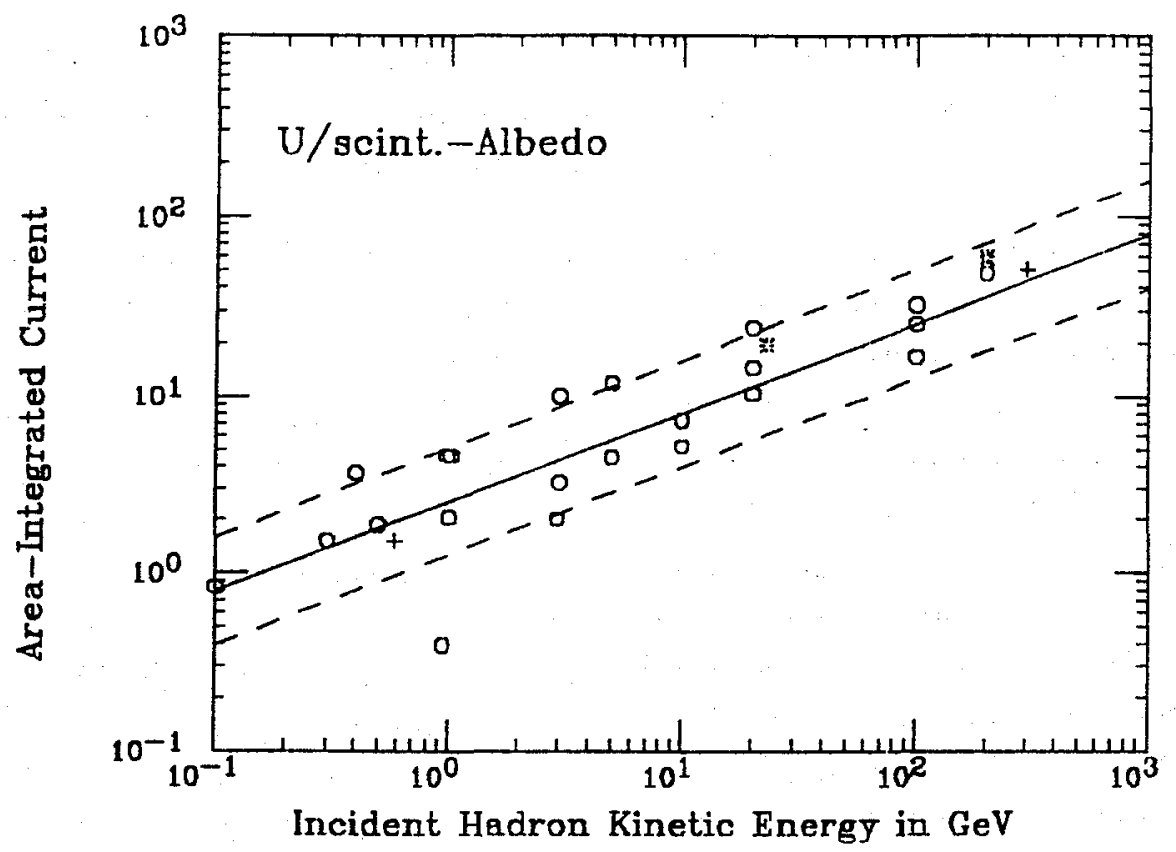

ligure 6: The number of albedo neutrons from a 11 ranium/scimbilator calorimeter. Open circles (o) are from Monte-Carlo simulations. Vertical crosses $(+)$ are experimental data

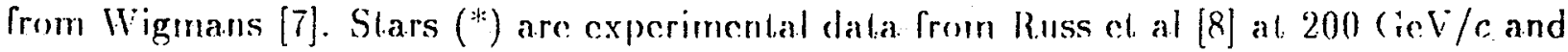
Fassò et al [9] a.t $24 \mathrm{GeV} / \mathrm{c}$. The solid line is the equalion $\int \mathrm{Ida}=2.5 \times(\mathrm{Fik} / 1 \mathrm{GeV})^{0.50}$, while the dashed lines are a factor of two higher and lower.

Again there is no reason to change the relation recommended by the Task (iroup for estimating the number of albedo neutrons:

$$
\int I d a=2.5 \times\left(b_{k} / I(\mathrm{icl} V)^{n .50}\right.
$$

where $E_{k}$ is the incident hadron energy. This corresponds to the current for an incident hadron fluence of $1 \mathrm{~cm}^{-2}$.

These estimates of the number of neutrons leaving the 'front' face of a calorimeler can be used to estimale the flucnce of neutrons inside the inner cavity. For a splicrical cavity and assuming isolropic emission of the neutrons from the front face, the average fuence of neutrons for a cavily radius of 2 metres will be $2 \times 10^{13} \mathrm{~cm}^{-2}$ for the standard LIIC operating conditions. Wilcox has shown that if there is no alsorbing matcrial in the inner cavity then the fluence at any point will be higher or lower than this average value by less than a factor of thee [12]. If the inner layer were to be lined with $10 \mathrm{~cm}$ of polyethylene, then the low-energy neutron fluence in the central cavity nould be reduced significantly [13].

In a recent experiment involving the present authors, a measurement was made of the reduction of the albede neutron flucnec by a $10 \mathrm{~cm}$ slab af polyelhylene placed in front of a lead calorimeler structure irradialed by 200 ( $\mathrm{cel} / \mathrm{e}$ prolons. Inilial results indicate a reduction factor of four in the neutron conergy range covered by indium activation detectors 
$(>0.8 \mathrm{MeV})$. This is consistent, with the Montc-Carlo results of Gabricl and Lillie given the different neutron energy ranges considered and the neglect, in the Monte-Carlo calculations of neuticons generated by high-energy interactions in the polythene.

The introduction of a neutron absorber will have other effects besides modifying the low-energy part of the albedo spectrum. Due to path-lenglh effects, albedo neutrons from points in the detector far away from the point of inlerest will be allenualed with respect to those originating ncarby. 'The SSC 'Task Group Report only considered an 'average' fluence of albedo neutrons in the cavity derived from the tolal number of neutrons leaving the inner surface of the calorimeler. However the sarne data (see Figure 6) can be used to calculate the fluence of albedo neutrons close to the calorimeter surface as a function of rapidity where only that part of the calorimeter close to the point of interest contributes to the albedo fluence. (The area-inlegrated albedo flucnee will be twice the actual number of neutrons (current) leaving the front surface). 'Th is is shown in Figure 7 for I,IIC conditions along with a horizontal line representing the 'average' value of the fuence in a cavity without an absorber. It will be seen that, as expected, the fluence al low rapidities is somewhat lower, but at the higher rapidities the fluence may be significantly higher in small localized regions.

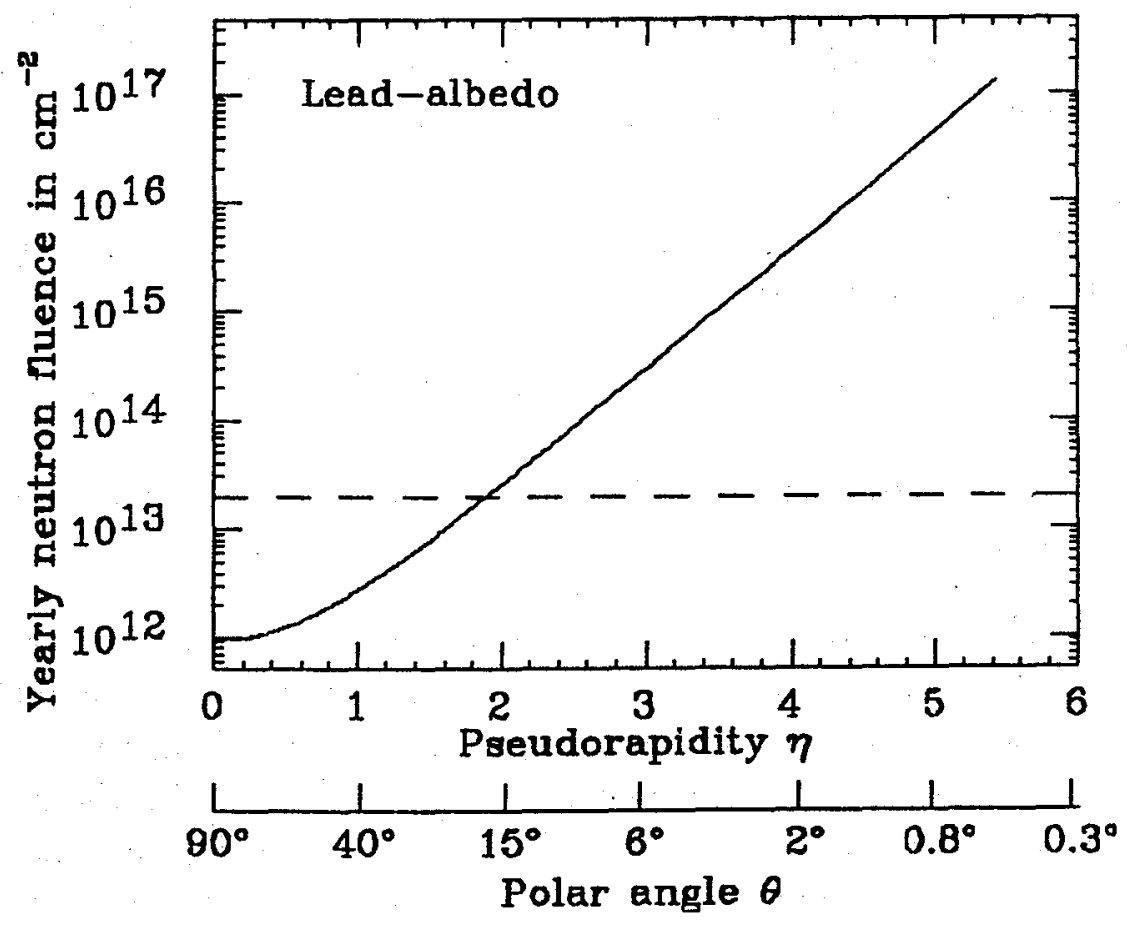

Figure 7: Annual alhedo neutron fuences in a spherical lead shell. The sphere has an inner diameter of 2 metres. Luminosity ele are for the reference LIIC working conditions (sec lexi). 
The fluence of albedo neutrons will also depend to some extent on the shape of the calorimeter. Present estimations have been made using a spherieal geometry where the hadrons from the p-p collisions are incident mormally on the calorimeter face. Most albedo neutrons will be emitied isotropically from the region of cascade maximum. Thus for a cylindrical geomelry, and especially al high rapidilies, the cascade maximum will be closer to the surface of calorimeter, so increasing the nentron escape probability. This effect necds to be quantified in future calculations.

\section{$5 \quad$ Acknowledgements}

The authors gratefully acknowledge the significant contribution to the calorimeler/neutron guestion made by the open discussions among the members of the SSC Task Group on Radialion levels in the SSC Interaction Regions. A special word of thanks is due to Don Groom whose insistence on clear thinking has led to a decper understanding of the problem.

\section{References}

[1] D. E. Groom (Ed.), Reporl of the. Task Group on Radiation Leucls in the SSC Interaction Regions, SSC Contral Design (iroup Report SSC-SR-1033 (1988).

[2] D. E. Groom, Nucl. Instrum. and Mcthods 1279 (1989) 1.

[3] J. Ranft and K. IIahn, ITUJE'T-8R, Sampling hadronic ancnts according to the dual topological unilarizalion of hard and soft hadronic: processes, (WRN Divisional Report TIS-R.P/218 (1988).

[1] K. O'Brien and J. E. Melaughlin, Nucl. Instrum. and Melhods 60 (1968) 129.

[5] K. O'Brien, Neulron spectra in. the side shicld of a large particle accricrator, IIcalth and Safely Jaboratory Reporl, New York, II ASI,-210 (197I).

[6] K. I'sch and J. M. Zazula, Shielding properlies of iron al high energy prolon accelcrators studied by a Monle. ('arlo code, DLSY Report. DESY 90-0.37 (1990).

[7] R. Wigmans, Eslimation of n.culron flux a.nd albcdo from actination analysis resulls, Appendix 18 in [1].

[8] J. S. Russ, G. R. Slevenson, A. Fassò, N. C. Niclsen, C. Furella, P. G. Rancoila and L. Vismara, Low-encrgy neulron measurcmenls in an iron calorimeler structure irradialed by 200 GeV/c hadrons, CLRN Divisional Report TIS-RT/89-02 (1989).

[9] A. Fassò, G. R. Stevenson, M. Bruzzi el al, Mlcasuremenls of lou-encrgy neulrons in an iron calorimeler slruclure irradialed by $2 /$ Gol\% protons, CFRN Divisional Report - in preparalion (1990). 
[10] J. M. Zazula and K. 'Tesch, Sludy of lhe newlron ficld from a hadronic cascade in iron: vcrification of a Monle (iarlo calculational model by compartison. with measured dala, DESY Report DESY 89-170 (1989).

[1.1] K. Foruno, J. R. Bran and II. Ilwang, Nculron flux suppression wilh polycthylene. modcralors in silicon hadron calorimelers, in WCFA Sludy Wock on Instrumentalion Technology for Iligh-I,uminosily Iladron Colliders, CFRN Rirport CERN 89-10 $(1989)$ p 325.

[12] T. P. Wilcox, Neulron. reflection in spherical calorimelcrs, $\Lambda$ ppendix 12 in [1].

[13] T. A. Gabricl and R. A. Lillic, Reduction of the neutron albedo in the vertex detector region of a generic SSC deleclor, SSC, Central Design (iroup Inlermal Nole SSC-NR$5.15(1.988)$. 